\title{
DOS VERSIONES DEL MODERNISMO: LA CONCIENCIA DEL TIEMPO EN RUBÉN DARÍO Y ANTONIO MACHADO
}

\author{
Carlos Javier Morales \\ Universidad San Pablo - CEU \\ Madrid
}

\begin{abstract}
A estas alturas de la historiografía y de la crítica sobre la literatura hispánica se va generalizando un discernimiento más o menos adecuado sobre la briosa transformación que experimentan nuestras letras entre la última década del siglo XIX y la primera del $\mathrm{XX}$, si bien no faltan antecedentes de primera fila que se constituyen en verdaderos iniciadores de lo que cristalizaría en el fin-de-siglo como un movimiento literario consumado y decisivo para las épocas venideras ${ }^{1}$. De aquel marchamo generacional inventado por Azorín a raíz de sus artículos de ABC, en 1913, sobre la nueva «generación del 98», surgió la dicotomía reduccionista entre Modernismo y 98, que en los años 30 trató de sustentar Pedro Salinas ${ }^{2}$ y que pervivió más radicalmente en los 50 a raíz del libro de Guillermo DíazPlaja Modernismo frente a $98(1951)^{3}$, entre otras muchas publicaciones. A pesar de la rectificación del propio Salinas en los años 40, está concepción dualista de nuestra literatura finisecular ofrecía innumerables escollos para su correcta comprensión. Gracias, en buena parte, a la labor de Ricardo Gullón ${ }^{4}$ - sin olvidar las elucidaciones anteriores de Federico de Onís
\end{abstract}

\footnotetext{
1 Aparte de la obra precursora de Bécquer, cuyo influjo en la lírica finisecular se hace cada vez más patente, debe reconocerse la obra plenamente modernista de autores americanos tan sobresalientes como José Martí y Manuel Gutiérrez Nájera, que ya han definido y practicado cabalmente la nueva estética antes de que Rubén Darío publique su Azul (1888). Cfr., entre otros estudios, el riguroso artículo de Ivan SCHULMAN, «José Martí y Manuel Gutiérrez Nájera: iniciadores del modernismo», en Revista Iberoamericana, vol. XXX, n. ${ }^{\circ}$ 57, año 1964, pp. 9-50.

2 «El problema del modernismo en España o un conflicto entre dos espíritus», recogido en su libro Literatura española. Siglo XX, Madrid, Alianza Editorial, 1970.

3 Madrid, Espasa-Calpe, 1966, 2.. ${ }^{a}$ ed.

4 Su libro más influyente en este sentido fue La invención del '98 y otros ensayos (Madrid, Gredos, 1969).
} 
y de Juan Ramón Jiménez-, en los años sesenta comienza a sentirse con urgencia la necesidad de analizar concienzudamente la cosmovisión y las propuestas literarias de modernistas y noventayochistas, con el objeto de justificar o desechar la supuesta dualidad. A la postre esta segunda opción ha resultado ser la más acorde con la realidad literaria de aquella época y ha propiciado muchas y fecundas posibilidades interpretativas de los autores en cuestión. Hoy la crítica más rigurosa prefiere utilizar el rótulo de modernismo o fin-de-siglo para denominar este brillante capítulo de nuestras letras a uno y otro lado del Atlántico ${ }^{5}$. No se trata, pues, de silenciar lo que de «noventayochismo» exista en la obra de Unamuno, de Azorín o de Antonio Machado, sino de comprender esta actitud de algunos autores españoles como una de las muchas direcciones que tomó el movimiento modernista y que en ningún caso se nos presenta como una categoría excluyente. Como nos aclara oportunamente Ricardo Gullón, «el modernismo es una época, en las letras españolas e hispanoamericanas, muy compleja y rica; el noventayochismo, una reacción política y social de escritores, artistas y pensadores españoles frente al Desastre. Es desacertado enfrentar fenómenos heterogéneos, y debemos aceptar, en todo caso, el segundo como uno de los elementos del primero» ${ }^{6}$. Se trata, pues, de una época literaria bien definida en el espacio y en el tiempo, con una comunidad indiscutible de rasgos cosmovisionarios y expresivos, a pesar de la multiforme realidad ideológica y estilística que nos ofrece cada autor. Y es que el modernismo, evitando por principio todo concepto de escuela, se nos presenta como el triunfo decisivo de la subjetividad y de la irracionalidad en el pensamiento y en la escritura, fenómeno que se encuentra en la base de toda la literatura moderna de Occidente.

Al fin y al cabo, no hacemos sino revalidar aquella célebre definición de Federico de Onís sobre el modernismo, publicada en 1934, que entiende esta época como «la forma hispánica de la crisis universal de las letras y del espíritu, que inicia hacia 1885 la disolución del siglo XIX y que se había de manifestar en el arte, la ciencia, la religión...» ${ }^{7}$. No termino esta cita tan conocida, pues con ella sólo pretendo destacar su acierto y advertir sobre las impropiedades en que incurre, pese a todo, la famosa defini-

\footnotetext{
5 Una concepción unitaria y esclarecedora de esta literatura finisecular la encontramos en los libros de Giovanni Allegra, El reino interior. Premisas y semblanzas del modernismo en España (Madrid, Eds. Encuentro, 1986), de Ricardo Gullón, Direcciones del modernismo (Madrid, Alianza Editorial, 1990, 3. ${ }^{\mathrm{a}}$ ed. aumentada) y de Hans HINTERHÄUSER, Fin de siglo. Figuras y mitos (Madrid, Taurus, 1980), entre otros trabajos. Cito los anteriores por haber enfocado global y sistemáticamente la producción literaria hispánica de estos años a ambos lados del Atlántico, ya sea con el rótulo de modernismo o de fin-de-siglo.

6 R. Gullón, Direcciones del modernismo, ed. cit., pp. 21 y 22. La cursiva es mía.

7 F. de ONís, Antología de la poesía española e hispanoamericana (1882-1932), Madrid, Publicaciones de la Revista de Filología Española, 1934, p. XV.
} 
ción. Es evidente, por una parte, que esta crisis ofrece manifestaciones afines en la ciencia, en la religión, en la política, en el arte, etc.; ahora bien, dentro de la literatura hispánica el modernismo posee una razón de ser y unos caracteres tan propios y precisos que requieren una explicitación más detallada en la anterior definición, aunque lo más oportuno sería proponer otra definición particular para el modernismo literario hispánico, pues de literatura hispánica hablamos tanto Onís como nosotros. Por lo demás, la concepción de Onís sigue siendo válida si despejamos otra pequeña pero muy importante vaguedad: como sabemos, Onís extiende esa «crisis» desde 1885 «hasta hoy», como acaba la conocida cita; entendiendo por «hoy» el momento en que publica tales palabras, en 1934. A cualquier conocedor de la historia literaria hispánica se le hace hoy inadmisible la extensión cronológica del modernismo hasta esa tardía fecha, a no ser que equipare absolutamente el modernismo con la posterior vanguardia, la cual ya también empieza a declinar en la España de 1934. Como ambos momentos, aunque anclados en idénticas raíces, presentan muchos rasgos diversos y hasta excluyentes, el ocaso del modernismo tendría que situarse mucho antes: como muy tarde, a finales de la segunda década de nuestro siglo.

Hechas estas salvedades introductorias, lo que me propongo en estas páginas es demostrar la unidad y diversidad del modernismo tanto en España como en nuestra América, cotejando dos volúmenes capitales de esta época literaria, correspondientes a un autor español y a otro americano y publicados en dos fechas muy cercanas: Soledades $(1902,1907)$, de Antonio Machado, y Cantos de vida y esperanza (1905). Por la necesaria limitación de espacio de este trabajo, así como por la importancia vital, literaria y metodológica que adquiere la cuestión del tiempo en la literatura moderna, me centraré en el análisis de la concepción del tiempo y de la conciencia subjetiva que del tiempo se forja el poeta, tal como se manifiesta en ambos libros centrales de la lírica hispánica de la época. Creo que con ello quedará confirmada la unidad y diversidad de ese modernismo que acontece en las letras de España e Hispanoamérica durante el período ya indicado.

Gracias a la crítica literaria de las últimas décadas, hoy podemos entender el modernismo literario hispánico como la reacción de unos escritores de volición radicalmente renovadora ante la crisis de ideales absolutos generalizada en la sociedad española y en la de aquellos países americanos más europeizados cultural y humanamente, así como una reacción consecuente contra aquellas formas literarias que esa sociedad burguesa ha favorecido. Las causas de esta crisis de ideales, expuestas en los libros citados más arriba y en algunos otros que resultan imprescindibles ${ }^{8}$, po-

8 Entre la extensa bibliografía sobre el tema, se hace indispensable citar el libro fundamental de Rafael GutiérREZ GIRARDOT, Modernismo (Barcelona, Montesinos, 1983), y el de Ángel RAMA, Rubén Darío y el modernismo (Caracas, Alfadil Eds., 1985, 2. ${ }^{\text {a ed.). }}$. 
drían resumirse aludiendo a la implantación del modelo burgués de sociedad propiciado por el liberalismo decimonónico y la revolución industrial, que conlleva una valoración de los productos artísticos por criterios meramente económicos y, por tanto, una conciencia de marginación social en el escritor más exigente. El positivismo, que en la segunda mitad del XIX se constituye en el método de todas las ciencias, triunfa asimismo en la filosofía y en los distintos «saberes del espíritu». Ese positivismo, que viene a ser la herencia del racionalismo físico-matemático que encauza la filosofía y la ciencia desde el siglo XVIII, supone una minusvaloración o una indiferencia científica generalizada hacia las cuestiones trascendentes y los ideales absolutos del espíritu humano, reduccionismo que está en la base de la gran rebeldía modernista. Paralelamente, la pérdida del sentido religioso y la consiguiente secularización de la vida agudizan en el poeta esta conciencia de desamparo y de insatisfacción ante las demandas más apremiantes del espíritu. Todo ello, en fin, desemboca en una crisis de valores absolutos y en la necesidad de que el espíritu individual del artista - del escritor, en nuestro caso- rellene ese vacío axiológico con una apasionada desconfianza en la razón y con un desarrollo de las potencias irracionales del hombre (el sentimiento, la memoria y la imaginación), a las que se les concederá un protagonismo casi desaforado (el casi desaparecerá en la época de las vanguardias).

A modo de estímulo de esa crisis (no ciertamente como causa), el desastre español del 98 agrava, en España y en Hispanoamérica, esa conciencia de crisis, pero entendiendo que esa conciencia, en sus niveles más profundos y raigales, ya había emergido con notable anterioridad.

Los modernistas intentarán satisfacer esa ansiedad de ideales absolutos a través de una conquista denodada y continua de la Belleza, concebida como medio de redención del individuo y de la sociedad. No por ello descartan la consecución del Bien y de la Verdad, pero estos dos últimos absolutos con frecuencia se supeditan al primero, pues el bien y la verdad también han sido el objeto del racionalismo, del utilitarismo, del positivismo y, en suma, de la sociedad burguesa que ellos detestan. El culto a la Belleza en sí constituye en esta época toda una rebelión (aunque anticipada por algunos románticos europeos), y de esta sublimación de la estética surgen nuevas formas de religiosidad y nuevos comportamientos morales ${ }^{9}$. En cualquier caso, de esta supremacía de la Belleza y de la moral estética que de ella dimana no podemos establecer una ley igualmente compartida por todos los modernistas. La unidad del modernismo no queda rota por su gran diversidad, y así como en España la conquista de la Belleza, del Bien y de la Verdad se encauza de manera distinta en Antonio y en Manuel Machado, en Unamuno, en Valle-Inclán y en Juan Ramón Jiménez,

9 Cfr. José Olivio JIMÉNEZ y Carlos Javier MORALES, La prosa modernista hispanoamericana (introducción crítica y antología), Madrid, Alianza Editorial, 1998, pp. 13-29. 
en Baroja y en Maeztu, también en Hispanoamérica encontramos un esteticismo decadentista (representado por Julián del Casal y José Asunción Silva, entre otros), un esteticismo idealista (donde cabría situar a Rubén Darío), un esteticismo de sólido compromiso moral (como ocurre en José Martí y José Enrique Rodó, los cuales comparten actitudes tan semejantes a las del «grave» Unamuno o a las del «noventayochista» Antonio Machado de Campos de Castilla, sin que por ello haya que eliminarlos de la nómina modernista, ni a los americanos ni a los españoles), y hasta podríamos hablar de un esteticismo escéptico (los casos del maduro Lugones o de Herrera y Reissig) y de un esteticismo espiritualista (el mexicano Enrique González Martínez, su compatriota Amado Nervo, el peruano José María Eguren, etc.). Rosa Rossi ha puesto de manifiesto la actitud decadentista que ostentan los «noventayochistas» españoles (incluidos Unamuno, Baroja y Azorín), en cuanto que recelan y hasta rechazan los patrones del positivismo y de todos los «ismos» que sostienen la sociedad burguesa de su tiempo ${ }^{10}$.

Sentadas estas advertencias sobre la supuesta dicotomía Modernismo y 98, demostraré la inexistencia de tal dualidad a través del análisis de la conciencia del tiempo en un poeta tan modernista como Rubén Darío y en otro tan «noventayochista» - según los reduccionismos de la crítica tradicionalista- como Antonio Machado.

\section{LA IMPORTANCIA DEL TIEMPO Y LA CONCIENCIA TEMPORALISTA DE LA POESÍA MODERNA}

Si la poesía moderna, incoada por los románticos ya a finales del siglo XVIII, puede entenderse como un progresivo derrumbamiento del racionalismo físico-matemático, generalizado por la Ilustración en todas las ciencias y en las diversas facetas de la vida, la consecuencia natural de este proceso será el creciente grado de irracionalismo que impregna tal poesía hasta su consumación en las vanguardias históricas de nuestro siglo $\mathrm{XX}^{11}$.

El irracionalismo, el despego hacia toda actividad y estructura de la razón, conlleva el rechazo de cualquier categoría abstracta (ley, juicio, concepto), de todo lo que el sujeto humano no puede concebir a partir de su espontánea y cambiante percepción sentimental. El irracionalismo conlleva, por tanto, el apartamiento de toda noción inmutable de la razón, empezando por la misma noción de ser (que ya el racionalismo la había

10 Cfr. Rosa Rossi, Da Unamuno a Lorca, Catania, Niccolo Gianotta Editore, 1967, pp. 27 y ss.

11 Este fenómeno lo ha explicado en pormenor Carlos Bousoño, a través de distintas obras. De modo monográfico lo aborda en El irracionalismo poético (el símbolo): Madrid, Gredos, 1981. 
puesto en entredicho como realidad extramental y la afirmaba como un mero -aunque necesario- ente de razón). La pérdida de la noción de ser como realidad estable a pesar de los accidentes de la Historia deviene en un generalizado desinterés por la noción también abstracta de esencia, de manera que la poesía moderna olvidará aquellos fenómenos de la esencia humana (en cuanto realidad inmutable) y atenderá casi exclusivamente a la existencia del individuo, única materia válida de conocimiento. Este oscurecimiento de la razón abstracta y universal en favor de la razón individual (o vital, según la terminología de Ortega), eleva a primer término el protagonismo del tiempo y de la consideración temporalista de la vida, pues el tiempo es la primera dimensión que se verifica en una concepción existencial de la vida humana, al contrario de la generalización atemporal del racionalismo. Como observa José Olivio Jiménez, «todos conocemos lo que ocurre cuando se quiere aplastar o callar a la otra razón, a la razón razonante, y cuando en su lugar nos proponemos mirar derechamente a la vida y al hombre de carne y hueso, como pedía Unamuno. Ocurre entonces que vemos tiempo, y nada más que tiempo. Esto lo sospechaba, o lo sabía, el racionalismo; y por eso había hecho abstracción en sus elaboradas construcciones de "ese pequeño detalle": el tiempo. Kierkegaard, desde antes, lo observó y lo anotó: El tiempo no se deja asignar ningún puesto en el pensamiento puro"» ${ }^{12}$.

Así lo percibió también muy pronto nuestro Antonio Machado, que inaugura la dimensión no ya temporal (que había existido siempre) sino temporalista de la poesía española: «Al borde de un sendero un día nos sentamos./ Ya nuestra vida es tiempo, y nuestra sola cuita/ son las desesperantes posturas que tomamos/ para aguardar... Más Ella no faltará a la cita» ${ }^{13}$. Pero esta percepción del tiempo se realiza, como es lógico, desde la individual $-\mathrm{y}$ existencial - conciencia del poeta, no desde las medidas de la razón físico-matemática. Así nos encontramos con que el poeta moderno, rebelde demoledor de las estructuras del racionalismo, despreciará la dimensión física o mecánica del tiempo, que es el tiempo útil para la sociedad burguesa, para ceñirse a la percepción subjetiva e interiorizada del tiempo, de su tiempo existencial, que de ordinario no coincide con el flujo temporal externo ${ }^{14}$. Y a esta variable percepción del tiempo en el poeta moderno corresponden dos estados vitales extremos, que son los que con frecuencia se constatan en el quehacer poético: la analogía y la ironía. Ambos conceptos, que aparecen ya definidos por los románticos alemanes,

12 José Olivio JimÉnEZ, Cinco poetas del tiempo, Madrid, Ínsula, 1972, 2. ${ }^{a}$ ed., p. 15.

13 A. MACHADO, «Soledades, galerías y otros poemas», en Poesías completas, ed. de Manuel Alvar, Madrid, Espasa-Calpe, Col. Austral, 1994, p. 109. El subrayado es mío. Citaré en adelante por esta edición.

${ }_{14}$ Cfr. Hugo FIEDRICH, Estructura de la lírica moderna, Barcelona, Seix Barral, 1974 , p. 33. 
han sido objeto de un estudio sugerente y minucioso por parte de Octavio $\mathrm{Paz}$, que concibe la dialéctica entre analogía e ironía como el fenómeno estructurador de la visión del mundo del poeta moderno (entendiendo por tal al romántico y a sus herederos hasta la época de las vanguardias históricas) ${ }^{15}$. La analogía, sintetizando mucho la reflexión de Paz de cara a nuestro interés concreto, podría definirse como la percepción armónica del mundo, en la que el poeta intuye la existencia de una esencia única del universo, que rige a todos los seres (sólo distintos en apariencia) a través de un ritmo perfecto; esencia y ritmo de los que el poeta forma parte comulgando en plena armonía con todo el cosmos. La analogía, desde el punto de vista psicológico, consiste en un estado sentimental privilegiado donde las potencias sensibles y emotivas del poeta actúan sobre la inteligencia para mostrarle un universo indiviso y gozoso. La analogía, por tanto, otorga a la percepción humana una extática experiencia en la que el sujeto se siente desvinculado de la ley física del tiempo sucesivo para instalarse en el disfrute de un instante armónico, que resulta ser el paralelo terreno más perfecto de nuestras ansias de eternidad, es decir, de nuestras ansias de aniquilar el tiempo, la dimensión física donde se sufre el cambio y la destrucción. La analogía será, en fin, el intento subjetivo por aprehender el universo como totalidad, una vez que el cientificismo racionalista, las formas de la vida urbana y burguesa y la pérdida del sentido religioso han desposeído al hombre de su confianza en un Ser supremo y de la satisfacción de sus ansias de totalidad. «La pérdida y abandono del centro - señala Francisco Jarauta refiriéndose precisamente a los poetas del fin-de-siglo-, de un logos poderoso y efectivo, hace que la misma filosofía se vea precipitada en el abismo/enigma de la experiencia, sin otra intención y programa que la de un obsesivo trabajo interpretativo de esos plurales órdenes abiertos en los que lo real deviene y se muestra» ${ }^{16}$.

La ironía viene a ser el envés de aquel supremo estado, es decir, la percepción del mundo como una infinita pluralidad de seres esencialmente distintos y contrarios, ante los que el poeta tiembla como un extraño en ese universo fragmentario y caótico. La ironía supone, pues, la constatación más dolorosa de la diferencia, sentida no ya como complementariedad, sino como oposición entre todas las fuerzas humanas y naturales. Y esa diferencia fatal, cuando no es consecuencia directa de la percepción del tiempo físico y sucesivo, al menos nos revela con mayor agudeza que nunca el carácter lineal y destructivo del tiempo, el cual nos presenta nuestra vida y la de los otros como una materia en irreversible descomposición. De ahí que el afán de todo poeta moderno sea precisamente el de rehuir ese

15 Cfr. Octavio PAZ, Los hijos del limo, Barcelona, Seix Barral, 1987, 2. a ed., pp. 89-114.

16 Francisco JARAUTA, «Fin- de siècle: ideas y escenarios», en José-Carlos MAINER y Jordi Gracia (eds.), En el '98 (Los nuevos escritores), Madrid, Visor, 1998, p. 18. 
momento irónico (entendiendo la ironía en su sentido trágico) para gozar de aquel instante de armonía suprema que la percepción analógica le proporciona. La poesía, no ya el texto poético como resultado, sino el fenómeno poético como proceso espiritual, será una lucha sangrienta contra el tiempo hasta conseguir aniquilarlo, siquiera sea instantáneamente. Esta lucha existencial puede adoptar diversos resultados en cada poeta y en cada poema, que será nuestro objeto de atención en las líneas que siguen.

\section{LA CONCIENCIA DEL TIEMPO EN DARÍO Y MACHADO}

A ningún lector de Antonio Machado se le escapa la certeza de que el tiempo no es sólo una dimensión constante y casi siempre explícita en su experiencia poética, sino que se constituye en tema vertebral de toda su obra, máxime después de leer los versos antes citados. Rubén Darío, en apariencia, no se encara directamente con el Tiempo, pero cualquier comprensión cabal de un poema suyo habrá de reconocer que es el Tiempo, con todas sus consecuencias, el fantasma del que el poeta, ora se muestra vencedor, ora sale huyendo de sus mortales amenazas. Toda la poesía de Darío es una esforzada tentativa de superar las dualidades experimentadas en su vida y en el cosmos a lo largo de su existencia: el Bien y el Mal, la Vida y la Muerte, el gozo del espíritu y el gozo de la carne ..., en definitiva, «la catedral y las ruinas paganas». Estas y otras dualidades se convierten en eje temático de numerosos poemas suyos, como el extenso «Coloquio de los centaruos» $\mathrm{y}$ «El reino interior».

Pues bien: tales dualidades, en el entender de Darío, sólo son fruto de ese gran criminal que es el Tiempo, entendido en su dimensión física y mecánica. Cuando Darío atribuye la visión de la armonía universal a unos centauros (poseedores de toda la energía física y sensual del caballo, a la vez que de la inteligencia y la voluntad del espíritu humano), lo que nos advierte - aunque sea de un modo sutil y subrepticio- es que tal armonía sólo es otorgada al hombre en unos instantes privilegiados, como privilegiados, en la carne y el espíritu, son los centauros, quienes habitan - no lo olvidemos- en una Isla de Oro, símbolo de lo extraordinario y casi inaccesible. Sólo ellos, y el ser humano cuando se desentiende de la sucesión temporal y de sus inevitables destrucciones, son capaces de afirmar con absoluta certeza que «la Muerte es de la Vida la inseparable hermana» y, más aún, que «la Muerte es la victoria de la progenie humana». «Mas he aquí que Apolo se acerca al meridiano» - apunta el poeta al final de la composición-, justo antes de que ese instante eterno y armónico, maravillosamente desligado de la sucesión temporal, se desvanezca y los centauros hayan huido a su templo secreto. Esta vez, como en casi toda la poesía mayor de Darío, el amenazante tiempo físico ha sido desafiado y 
abolido. En otros momentos, aislados en la totalidad de su obra, nos situaremos ante el rotundo fracaso irónico del poeta; pero no es necesario llegar a estas contadas composiciones, pues en los demás poemas, por gozosa y divina que resulte su experiencia vital, enseguida intuimos que la ansiada analogía se hace realidad en un instante concreto y, como tal, temblorosamente abocado a la provisionalidad y a la caída.

Ese extático goce de la analogía, que trasciende el simple placer sensible hasta llegar al máximo grado de conocimiento (o, mejor, donde el placer, sensual y espiritual, se alía con el sumo conocimiento), ese extático goce - digo - se produce en Rubén Darío a través de la vivencia erótica y de la experiencia propiamente poética, que con frecuencia le conduce a la recreación subjetiva y artística del pasado, donde todos los tiempos se convocan en un solo instante y son rescatados del polvo acumulado por la Historia. De manera que es en los poemas más intensamente eróticos o en los más ostentosamente culturalistas (si es que ambos fenómenos no coinciden en un mismo poema) donde Darío accede a esa anulación momentánea del Tiempo y se hace acreedor de una provisional eternidad. Así podemos advertir, de cara a una lectura coherente y eficaz de su obra, que el tan célebre exotismo de Darío no es nunca un juego banal o un escapismo más o menos placentero de las «eternas cuestiones» del hombre: tan intenso será su exotismo y refinamiento culturalista cuanto más intenso sea su drama interior contra el Tiempo y, en algunos casos, contra ese tiempo maldito «en que le tocó nacer». «El estetismo de Darío - apunta muy oportunamente Giovanni Allegra-, nos lleva a comprender cómo, para él, la superación de la categoría temporal, que está implícita siempre en sus mejores versos, es un reflejo de opciones estéticas y espirituales tan sinceras como inequívocas» ${ }^{17}$.

Una experiencia propiamente poética donde Darío construye un refinadísimo «paisaje de cultura», la encontramos en el célebre poema «Era un aire suave...», de Prosas profanas. Maldad y Belleza se alían en la «divina Eulalia», de una forma tan misteriosa como seductora; y la reconciliación de Maldad y Belleza conlleva automáticamente, según el pensar poético de Darío, la superación de la dualidad Maldad-Bondad. Pues bien: tan prodigioso fenómeno de suprema armonía sólo se produce mediante la destemporalización y eternización artística de la escena, es decir, situando la seducción y el triunfo de la divina Eulalia en un tiempo ahistórico, desvinculado de las limitaciones propias de la contigencia histórica. Observemos la gozosa duda final del yo-poético, que trata inútilmente de poner lugar y fecha a la escena que nos ha representado magistralmente:

17 Giovanni Allegra, El reino interior. Premisas y semblanzas del modernismo en España, Madrid, Eds. Encuentro, p. 174. 
¿Fue en ese buen tiempo de duques pastores, de amantes princesas y tiernos galanes, cuando entre sonrisas y perlas y flores iban las casacas de los chambelanes?

¿Fue acaso en el Norte o en el Mediodía?

Yo el tiempo y el día y el país ignoro; pero sé que Eulalia ríe todavía, ¡y es crüel y eterna su risa de oro! ${ }^{18}$

Tal prodigio de encarnación de la crueldad y de la belleza (y, por tanto, de la bondad) en una misma persona, así como su triunfo sobre las limitaciones de este mundo, simbolizado por la constante risa, sólo puede acontecer en un presente eterno desligado de nuestras agobiantes ataduras temporales.

En un polo opuesto al de esta analogía dariana, encontramos, a modo de inquietante conlusión del mismo volumen poético, el irónico soneto «Yo persigo una forma...». La ansiedad de Belleza que consume al yo lírico esta vez no consigue encarnarse en una forma poética adecuada, esto es, en un ritmo perfecto que exprese la armonía o analogía de todos los seres del universo. El yo lírico siente dentro de sí un deseo insaciable de comunión con el cosmos, concebido como Belleza suma, pero lo que verifica en su experiencia vital, corroída por el Tiempo, es la fragmentaria realidad del Universo y la distancia abismal entre el yo y el mundo. Revisemos los momentos clave de este proceso. En el primer cuarteto se nos presenta el estado ansioso del poeta, a la vez que se nos advierte sobre la dificultad de su empresa creadora:

Yo persigo una forma que no encuentra mi estilo, botón de pensamiento que busca ser la rosa; se anuncia con un beso que en mis labios se posa al abrazo imposible de la Venus de Milo ${ }^{19}$.

El siguiente cuarteto nos transmite toda la intensidad de esa ambición interior, para luego, en el primer terceto, dar cuenta de la imposibilidad de realizar esa aventura estética:

Y no hallo sino la palabra que huye,

la iniciación melódica que de la flauta fluye

y la barca del sueño que en el espacio boga;

y bajo la ventana de mi Bella-Durmiente,

el sollozo continuo del chorro de la fuente

y el cuello del gran cisne blanco que me interroga ${ }^{20}$.

18 Rubén DARío, «Prosas profanas», en Poesía, ed. de Pere Gimferrer, Barcelona, Planeta, 1987, p. 39. Los subrayados son míos. Citaré en adelante por esta edición.

19 Ibid., p. 94.

20 Ibid. La cursiva es mía. 
He subrayado los dos versos últimos porque son los que, por vía simbólica, nos explicitan las causas (¿o las consecuencias?) de ese fracaso. En primer lugar, «el sollozo continuo del chorro de la fuente» origina la emoción de un «fluir suave»y, a la vez, «continuo», esto es, la sensación de un "goteo ininterrumpido» que alude indiscutiblemente a la sucesión del tiempo físico y lineal, donde todo tiene un antes y un después y donde nada es igual antes que después. Y, de otra parte, ese cuello blanco de cisne, que en el mismo libro había servido a Darío para expresar la consumación de la armonía universal, ahora, en un polo opuesto, nos representa la distancia insalvable entre el yo-poético y el cisne. El cisne, en efecto, se ha convertido en una constante e inquietante pregunta, en una duda que aborta cualquier intento de comunicación y, por supuesto, cualquier intento de comunión. Si el cisne, teniendo en cuenta su reiterada significación simbólica dentro de las mismas Prosas profanas, representa al Universo en lo que tiene de perfección y de belleza, se deduce que la angustia del poeta proviene de una frustrada e imposible comunicación y comunión con el cosmos: es decir, nos hallamos ante el revés de la analogía antes observada. Por efecto del Tiempo, que se hace presente en la conciencia del poeta, se imposibilita la consecución del instante eterno donde todas las cosas comulgan y se accede al estado de conciencia irónica, en el sentido trágico que vengo atribuyendo a este concepto.

En Antonio Machado, aunque con un desarrollo distinto (según veremos bajo el siguiente epígrafe), también podemos constatar la presencia de ambos estados extremos, en los que el Tiempo, de un modo aún más explícito, ejerce de ordinario la principal causalidad. Si toda la poesía de Machado es un recuento artístico de su pasada experiencia vital, es lógico que sea el Tiempo -en su fluencia física o en su congelación subjetiva en la conciencia del yo-lírico- el que posibilite esta perspectiva del poeta. Es sabido que en Antonio Machado el pasado vital contenido en su memoria se transforma en una materia nueva, que puede producir desconsuelo, angustia $\mathrm{o}$, por el contrario, exaltación anímica y espiritual. $\mathrm{Y}$ es que los hechos pasados albergados en su memoria son modificados -a veces sustancialmente- por el sueño (símbolo de la imaginación creadora) o por el amor, realidad vital que transmuta toda la memoria y le confiere un contenido nuevo o un sentido emocional radicalmente distinto; hasta tal punto que el amor, por su poder transformador del pasado y del presente biográficos, puede confundirse con el sueño o con la fantasía, como nos declara el poeta en esta afirmativa - y analógica - canción a Guiomar:

Todo amor es fantasía; él inventa el año, el día,

la hora y su melodía;

inventa el amante y, más, 
la amada. No prueba nada, contra el amor, que la amada no haya existido jamás ${ }^{21}$.

El amor, pues, tiene como efecto primero y primordial el de reorganizar subjetivamente el tiempo y, con él, toda la realidad vivida hasta entonces; la cual canta o inventa, en virtud de la nueva conciencia temporal, una melodía también nueva que satisface toda la ansiedad del yo-poético. Nos encontramos ante uno de esos accesos machadianos a la analogía universal, que ha tenido como causa el amor erótico y el sueño generado por tal amor; y, como efecto, la distinta apreciación del tiempo y, con él, de toda la realidad vivida. De un modo semejante sucede en el célebre poema «A José María Palacio», de Campos de Castilla. Aquí la analogía se hace más explícitamente universal, por cuanto se refleja en los más variados seres de la Naturaleza. Esta composición reviste una importancia capital para nuestro asunto en cuanto que versa sobre la omnipresente tierra soriana de Campos de Castilla y, a diferencia de su percepción habitual de la misma, la emoción suscitada por ella empieza y termina en una gozosa afirmación de la fertilidad de la Naturaleza y de su inagotable energía vital. No es que Soria se nos ofrezca habitualmente como el símbolo de la derrota y la destrucción del ideal, pero sí que normalmente constituye el escenario de la angustia existencial experimentada por el poeta, ya esté presente en Soria ya esté en sus tierras andaluzas remordido por la nostalgia de las «tierras altas». En esta composición, en cambio, observaremos que la naturaleza soriana, en virtud del amor (el amor a la difunta Leonor enterrada allí), aparece despojada de la dimensión temporal en su faceta destructora y dramática y se nos muestra como el espacio reconfortante donde un tiempo cíclico - no sucesivo y lineal- renueva de continuo a una naturaleza siempre fecunda y pletórica de vida:

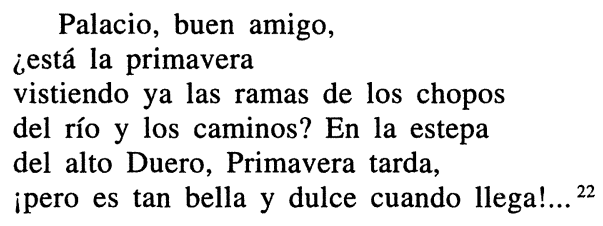

La acción del tiempo no se concibe como una erosión devastadora de la realidad natural ni espiritual, sino como un ciclo cuya finalidad es devolver la belleza y la alegría al corazón humano a través de la fecundidad incesante de una Naturaleza armónica, de una armonía en la que el Yo y la Naturaleza participan plenamente:

21 Poesías completas, ed. cit., p. 386. El subrayado es mío.

22 Ibid., p. 215. 


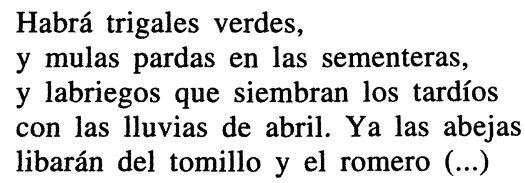

Puesto que los efectos de esa Primavera «tardía» de los campos sorianos aún no han llegado a consumarse, el tiempo cíclico aún no ha alcanzado su cúspide de fruición natural y espiritual, aún no ha llegado al instante de plenitud vital en la que se experimenta prodigiosamente la analogía del Universo. Pero el poeta, en virtud de la esperanza alcanzada por el amor, anuncia que ese acontecimiento supremo se cumplirá en un futuro ya muy próximo:

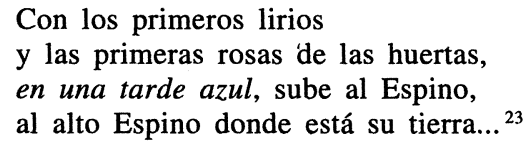

La ya difunta Leonor, que podría ser el motivo para una rotunda y angustiosa elegía, se encuentra -o se encontrará, cuando se cumpla ese futuro ya próximo - plenamente viva, intemporal o eternamente viva en «el alto Espino donde está su tierra». Ese día la tarde estará azul, un eficacísimo desplazamiento calificativo que extrae la cualidad del cielo primaveral para atribuírsela a la entera tarde $\mathrm{y}$, con ella, simbólicamente, a todo el universo; con toda la satisfacción anímica que el azul nos proporciona. La analogía universal y la consiguiente congelación del tiempo lineal y sucesivo está a punto de realizarse.

Sobra aducir cualquier ejemplo donde la conciencia de Machado experimente ante el tiempo un fenómeno contrario, el de la ironía destructora. Hasta aquí sólo he pretendido verificar cómo en ambos poetas, Darío y Machado, el tiempo se representa según dos perspectivas: la analógica (resultado de una contemplación instantánea e inmóvil del tiempo) y la irónica (proveniente de la percepción de un tiempo lineal y sucesivo). Y lo más relevante con respecto a la historia literaria hispánica es que esa doble concepción del tiempo, aunque dependa de unas causas biográficas y extrapoéticas que son innegables, procede ante todo de las potencias irracionales del poeta (sentimiento, memoria e imaginación), que ahora, en el modernismo, han desoído los dictados de la razón físico-matemática (que obra por abstracción y generalización) y se han desplegado con una fuerza sublime, desconocida en la poesía hispánica anterior al modernismo.

23 La cursiva es mía. 


\section{DesarRollo DE la Dialéctica TEMPoRAL EN DARÍo Y MACHADO}

A pesar de las coincidencias epocales y estéticas de ambos poetas, decididamente modernistas uno y otro, el modo en que cada uno se enfrenta al Tiempo a largo de toda su trayectoria lírica es notablemente distinto, y es lo que determina la individualidad y la personalidad poética de cada uno, a pesar de su comunidad de rasgos cosmovisionarios y estéticos, como ocurre en todos los autores modernistas de primera fila. Es más: del modo peculiar en que cada poeta, aquí Darío y Machado, encare el drama del Tiempo depende su posición concreta ante las distintas cuestiones esenciales de la vida, y hasta la frecuencia de unos temas en lugar de otros. Así en Rubén Darío los temas de la música, del erotismo sublime y sagrado, de la belleza ideal y sensible, adquieren un protagonismo muy distinto al del caso de Machado, donde - además del tiempo mismo- la soledad, la muerte y la búsqueda de Dios predominan como temas concretos en todo el cuerpo de su obra (aunque no excluyen los otros, como sucede igualmente en el caso de Darío).

Y es que para trazar la visión del mundo de un autor, así como su pensamiento poético, es decir, la sabiduría humana vertida en su obra lírica, es preciso tomar en consideración la totalidad de su obra, ya que un libro complementa y, a la vez, modifica al anterior. También cabe advertir que cada poema es complementado y modificado por los restantes del mismo libro. Por tratarse de dos colecciones eminentemente modernistas y cronológicamente muy cercanas, además de fundamentales en la producción de cada autor, señalaré cómo se desarrolla esa dialéctica temporal de Darío y Machado a través de dos volúmenes muy concretos: Cantos de vida y esperanza (1905) y Soledades, galerías y otros poemas (de 1902, aunque revisado y ampliado en la edición de 1907), respectivamente.

Rubén Darío, que en su poema «Dafne», de Prosas profanas, había anunciado que «al canto mío el tiempo parecerá más breve», en los Cantos de vida y esperanza atenuará esta victoria constante sobre el tiempo, aunque ello no obsta para que profiera, con el mismo optimismo estético de siempre, este analógico e intemporal soneto de la serie «Los cisnes», que comienza desplazándose del momento real para situarse en un instante estético e imperecedero:

Por un momento, joh Cisne!, juntaré mis anhelos a los de tus dos alas que abrazaron a Leda,

y a mi maduro ensueño, aún vestido de seda dirás, por los Dioscuros, la gloria de los cielos ${ }^{24}$.

${ }^{24}$ Op. cit., p. 116. 
El yo-poético abandona su temporalidad histórica para instalarse en el presente intemporal del arte, como sucede en tantos otros poemas suyos. Gracias a ese desplazamiento que sólo por el arte se hace posible, el poeta podrá revivir aquel instante supremo y mítico en que el Cisne-Zeus invade audazmente la secreta intimidad sexual de la hermosa Leda:

Es el otoño. Ruedan de la flauta consuelos. Por un instante, joh Cisne!, en la oscura alameda sorberé entre dos labios lo que el Pudor me veda, y dejaré mordidos Escrúpulos y Celos.

Cisne, tendré tus alas blancas por un instante y el corazón de rosa que hay en tu dulce pecho palpitará en el mío con su sangre constante.

Dentro de esa nueva temporalidad a la que el poeta accede, el instante de plenitud sexual y amorosa podrá congelarse en una duración distinta, en cuanto que está libre de la destrucción del antes y el después, como si se tratase de una eternidad divina que también contuviera los goces sumos de este mundo terreno, pues sólo esos goces pueden suscitar en nosotros, hombres mortales, la imaginación de una dicha suprema. De ahí que el «corazón de rosa pueda seguir palpitando con su sangre constante», lo cual supone una suerte de duración que, sin embargo, no elimina la máxima intensidad placentera de ese instante privilegiado. Observemos la nueva alusión temporal del último verso, donde el ritmo peculiar de la fuente de diamante resulta sustancialmente distinto del ritmo propio del tiempo en su dimensión física y sucesiva:

Amor será dichoso, pues estará vibrante el júbilo que pone al gran Pan en acecho mientras su ritmo esconde la fuente de diamante.

Por lo visto hasta aquí, y teniendo en cuenta el resto de la producción lírica de Darío, se puede afirmar que toda la poesía del nicaragüense - también los Cantos de vida y esperanza - se halla destinada a eliminar de la existencia ese tiempo físico, lineal y erosivo, para gozar - aunque de modo provisional, precario y siempre amenazado-, de un instante supremo de placer que lo libere de la sucesión y de la destrucción del tiempo $^{25}$. La prueba de esta vocación atemporal de la poesía de Darío se halla en los mismos poemas donde la ansiada analogía del instante no llega a consumarse. $Y$ es que en esos poemas el yo-lírico identifica su fracaso (explícita o implícitamente) con su incapacidad para desligarse de las atadu-

${ }^{25}$ Cfr. José Olivio JiMÉNEZ, «Martí, Darío y la intuición modernista de la armonía universal», en La raíz y el ala: aproximaciones críticas a la obra literaria de José Martí, Valencia, Pre-textos, 1993, pp. 289-299. 
ras del tiempo físico y acceder al «ritmo secreto» de la Naturaleza, concebida como una esencia única, eterna $y$, en cuanto tal, inexpugnable ante los embates del tiempo. De manera que su comunicación y comunión con la Naturaleza, su disfrute de la analogía universal, conlleva también el abandono del tiempo lineal y el acceso al tiempo cíclico y reversible donde los instantes de plenitud gozosa se repiten eternamente. En el siguiente poema de los Cantos..., titulado «Caracol» y dedicado precisamente a Antonio Machado, el yo-poético se sirve de un elemento de la Naturaleza, el caracol, para comulgar con toda ella y con los dioses que viven fuera de nuestro tiempo:

En la playa he encontrado un caracol de oro macizo y recamado de las perlas más finas; Europa le ha tocado con sus manos divinas cuando cruzó las ondas sobre el celeste toro.

He llevado a mis labios el caracol sonoro y he suscitado el eco de las dianas marinas; le acerqué a mis oídos, y las azules minas me han contado en voz baja su secreto tesoro.

Así la sal me llega de los vientos amargos que en sus hinchadas velas sintió la nave Argos cuando amaron los astros el sueño de Jasón;

y oigo un rumor de olas y un incógnito acento y un profundo oleaje y un misterioso viento... (El caracol la forma tiene de un corazón) ${ }^{26}$.

El poeta, a través del caracol, se siente parte de la esencia única del cosmos, algo que se viene anunciando desde la mención de las perlas finas, las dianas marinas, las azules minas, el profundo oleaje, etc., y que llega a expresarse de modo absoluto en el último verso, escrito entre paréntesis por tratarse de una conclusión implícta en todo el discurso anterior: en efecto, «el caracol la forma tiene de un corazón». El caracol, por su esencia amorosa, da cohesión a todos los seres de la Naturaleza (pasados, presentes y futuros) y - lo que es más importante- realiza la unión esencial entre el yo-poético y ese mundo esencialmente armónico y amoroso. La inserción de personajes míticos realza ese poder atemporalizador con que el caracol y - por medio de él- todo el poema han liberado al yo-lírico de su limitada condición temporal.

Por esa vocación de atemporalización y búsqueda del instante de plena armonía, la poesía de Darío se halla poblada de personajes mitológicos y de todos los personajes y paisajes de la cultura más diversa en el espacio y en el tiempo, tanto más seductores cuanto más remotos sean a nuestro entorno inmediato y vulgar. Esta filtración libresca de todas sus inquietu-

26 Op. cit., p. 140. 
des vitales, lejos de manifestar un escapismo lúdico —como tan injustamente se ha denunciado-, nos revela, por vía indirecta pero eficacísima, la magnitud de su angustia existencial. Sólo que esa angustia se expresa ex contrario, es decir, representando el goce físico y espiritual con que el poeta ha logrado superarla por un instante, que es precisamente el instante del poema. Se diría, por tanto, que Darío tiende a constatar poéticamente los aislados instantes de la analogía existencial, y de ahí la exaltación habitual de sus poemas, aunque en su existencia lo habitual será precisamente la desazón vital y la percepción de la ironía, estado que el poeta, de ordinario, prefiere silenciar en sus versos. No obstante, el propio contexto de sus poemas más jubilosos nos advierte que esa «celebración de la armonía» constituye un instante aislado en su trayectoria existencial. Y es que siempre podemos encontrar una alusión, más velada o más explícita, a la situación irónica y al tiempo físico que el poema pretende eludir. Basta con recordar el comienzo de los dos sonetos reproducidos más arriba: «Por un momento, joh Cisne!, juntaré mis anhelos», «En la playa he encontrado un caracol de oro». En definitiva, siempre se vislumbra la rareza de la experiencia poética representada.

Ya veremos que tal actitud no es constante en toda su obra, pero sí es la más frecuente y la más característica, la que mejor define su personalidad espiritual y poética.

En Antonio Machado, por su propia personalidad (y no por un supuesto «noventayochismo» que tantas veces se le atribuye), la solución del problema suele ser la contraria a la de Darío. Pero el problema sigue siendo el mismo y semejantes son sus circunstancias estéticas e históricas. En el poeta sevillano la conciencia de la inquietud existencial presente le impulsa a la contemplación de su pasado, un pasado que podemos calificar de poético en cuanto que no se ajusta a la realidad fáctica y emocional de lo que realmente le aconteció, sino a la reconstrucción de su pasado real mediante una memoria condicionada por la índole de la emoción vital que le invade en el presente. $\mathrm{Y}$ al mirar al pasado existencial condicionado por la emoción de desazón vital presente, lo que se produce es un ensanchamiento y un recargamiento de la conciencia temporalista, que le impele a esculpir con una gravedad mayor esa acción destructora del tiempo en su propia vida. De ahí que el tiempo se convierta en tema principal de muchos poemas suyos y que, con él, emerjan otros temas afines: la conciencia de la soledad y de la muerte y la busqueda de un Dios que sea refugio ante esa irreparable destrucción del tiempo.

De manera que lo habitual en su poesía - aunque tampoco excluyente- sea la expresión de una percepción irónica de la vida, en el sentido trágico que vengo atribuyendo a este concepto. $\mathrm{Y}$, por hallarse anclado más reciamente que Darío en la más genuina tradición romántica, Antonio Machado suele situar la destrucción del tiempo en su existencia personal y 
en la existencia humana en general, casi nunca en la Naturaleza, que es el mundo de la armonía analógica del que él se siente desterrado. La comunión Yo-Mundo, fenómeno culminante del proceso analógico, raras veces se produce en Machado, por mucho que el sueño poético y el amor erótico traten de rescatarlo de esa conciencia existencialmente postrada ante la erosión del tiempo, aunque moralmente sea fuente de valores muy positivos. Podemos ilustrar muy bien esa lucha existencial por superar la conciencia negativamente temporalista con el primer poema de Soledades, «El viajero». Machado, a través del protagonista poemático, contempla el pasado con la intención de reconstruirlo en un futuro inicialmente esperanzador. Veamos el resultado de este intento:

Está en la sala familiar, sombría, $\mathrm{y}$ entre nosotros, el querido hermano que en el sueño infantil de un claro día vimos partir hacia un país lejano.

Hoy tiene ya las sienes plateadas, un gris mechón sobre la angosta frente; y la fría inquietud de sus miradas revela un alma casi toda ausente.

Deshójanse las copas otoñales del parque mustio y viejo.

La tarde, tras los húmedos cristales, se pinta, y en el fondo del espejo.

El rostro del hermano se ilumina suavemente. ¿Floridos desengaños dorados por la tarde que declina? ¿Ansias de vida nueva en nuevos años? ¿Lamentará la juventud perdida? Lejos quedó - la pobre loba- muerta. ¿La blanca juventud nunca vivida teme, que ha de cantar ante su puerta? ¿Sonríe el sol de oro

de la tierra de un sueño no encontrada; y ve su nave hender el mar sonoro, de viento y luz la blanca vela hinchada?

Él ha visto las hojas otoñales, amarillas, rodar, las olorosas ramas del eucalipto, los rosales que enseñan otra vez sus blancas rosas...

$Y$ este dolor que añora o desconfía el temblor de una lágrima reprime, y un resto de viril hipocresía en el semblante pálido se imprime.

Serio retrato en la pared clarea todavía. Nosotros divagamos. En la tristeza del hogar golpea el tictac del reloj. Todos callamos ${ }^{27}$.

27 Poesías completas, ed. cit., p. 88. 
La complejidad psicológica y estética del poema, en medio de su aparente sencillez, hace imposible cualquier comentario analítico en la extensión de estas páginas. Pero para el objeto que nos ocupa bastará con señalar los dos fenómenos que, a mi juicio, originan la tensión dramática de todo el texto. El primero es evidente en una primera lectura: la imposibilidad de reproducir en la existencia humana la lección ejemplar de la Naturaleza, capaz de renacer a pesar de la destrucción del Tiempo. El segundo, fuertemente aliado con el anterior, reside en la capacidad que tiene el sueño para modificar el pasado (¿Floridos desengaños/ dorados por la tarde que declina?) y el futuro (y ve su nave hender el mar sonoro/ de viento y luz la blanca vela henchida). El poeta es consciente $-\mathrm{y}$ aquí radica, entre otros factores, la modernidad del poema - de que el pasado es irrecuperable por la memoria, la cual siempre actúa sobre lo vivido desde la conciencia presente, que tiñe la existencia anterior de una valoración positiva o negativa con independencia del valor real -incognoscible para el poeta moderno- que tuvieron los hechos pretéritos. De ahí que el sueño sobre el pasado (esto es, la redención del pasado a través de la memoria) también pueda proyectarse hacia el futuro y generar una esperanza emotiva, pues no se apoya en ningún hecho externo y trascendente a la propia emoción. Y precisamente porque lo que se verifica externamente contradice a lo esperado por el sueño ( $\ll$ En la tristeza del hogar golpea/ el tictac del reloj...), el espíritu del protagonista sucumbe ante esa irrefutable acción destructora del tiempo. La ironía, en suma, triunfa sobre la memoria y sobre la esperanza.

Que el tiempo físico, sucesivo y lineal, es ininterrumpido e ininterrumpible es una convicción recurrente en casi toda la poesía de Machado. Diáfanamente podemos volver a comprobarlo en otro poema de las Soledades:

Era una mañana y abril sonreía.

Frente al horizonte dorado moría

la luna, muy blanca y opaca; tras ella, cual tenue ligera quimera corría la nube que apenas enturbia una estrella.

Como sonreía la rosa mañana al sol del Oriente abrí mi ventana y en mi triste alcoba penetró el Oriente en canto de alondras, en risa de fuente $y$ en suave perfume de flora temprana.

Fue una clara tarde de melancolía. Abril sonreía. Yo abrí las ventanas de mi casa al viento... El viento traía perfume de rosas, doblar de campanas..

Doblar de campanas lejanas, llorosas, suave de rosas aromado aliento... 
....¿Dónde están los huertos floridos de rosas? ¿Qué dicen las dulces campanas al viento?

Pregunté a la tarde de abril que moría: ¿Al fin la alegría se acerca a mi casa? La tarde de abril sonrió: La alegría pasó por tu puerta -y luego, sombría: Pasó por tu puerta. Dos veces no pasa ${ }^{28}$.

Si bien la Naturaleza ha reconfortado al poeta con su renacimiento matinal y la serena emanación sensorial de una de sus tardes, de manera que el yo-lírico ha conseguido olvidar por unos instantes «su triste alcoba» y su melancolía personales, esta alegría propiciada por la contemplación fugitiva de unos instantes de armonía natural se presenta como un fenómeno temporal abocado a la irreversibilidad del tiempo sucesivo y lineal: la alegría, en efecto, «dos veces no pasa».

Y esta reconstrucción del pasado personal de Machado - a diferencia del pasado cultural y artístico de Darío- es la que condiciona su particular conciencia del tiempo, agudamente dramática y destructiva, por más que el sueño de su mirada poética y la reanimación espiritual del amor traten de contrarrestar esa amarga experiencia temporalista.

\section{AFINIDADES DARÍO-MACHADO EN LA CONCIENCIA DEL TIEMPO}

Creo que estas diferencias psicológicas y estéticas de ambos poetas, que determinan el desarrollo peculiar de la dialéctica del tiempo en su poesía, no han alcanzado a empañar, por lo expuesto hasta aquí, la semejanza de su drama espiritual, de su cosmovisión epocal y de su ideario poético. En efecto, ya he señalado que en ambos autores subsiste una creencia, más implícita o explícita, en la realidad salvadora de un tiempo cíclico y perfecto (cristalizado en un instante de plenitud) que redime al hombre y al mundo de las amputaciones obradas por la Historia, esto es, por ese tiempo lineal y sucesivo que agudiza nuestra conciencia de la muerte. En otras palabras: tanto para Darío como para Machado la poesía consiste en una aprehensión (por tanto, subjetiva y espiritual) de la analogía del universo, frente a la experiencia irónica y fragmentaria que el poeta advierte en el mundo a través de sus circunstancias cotidianas e históricas, regidas por los efectos de un tiempo sucesivo y devastador. Cada autor, por su psicología y sensibilidad individuales, puede resultar más proclive a expresar la victoria del instante de armonía cósmica o a constatar la derrota de sus potencias irracionales (sentimiento, memoria e imaginación) en su lucha contra el tiempo físico y sucesivo; y así ocurre de hecho en los casos de

\footnotetext{
28 Ibid., p. 117.
} 
Darío y de Machado. Pero lo importante ahora es advertir que en ambos poetas modernistas se mantiene esa misma ansiedad y esa dualidad de dimensiones en la conciencia del tiempo.

Por eso observaremos a continuación, sin separarnos de los Cantos... ni de las Soledades, cómo Darío puede ofrecernos un resultado poético más «machadiano» y cómo Machado puede aproximarse en varios casos al desenlace «dariano» en su lucha contra el tiempo.

En primer lugar (aunque no voy a concederle aquí la atención que esta cuestión merecería) existen poemas de Darío, especialmente en el volumen que aquí nos ocupa, donde el bardo nicaragüense trata de descender de la rueda de su tiempo cíclico y eterno para encararse de inmediato con la circunstancia histórica de los países hispanoamericanos al comienzo de nuestro siglo, cuando el desastre del 98 le hace más consciente de la amenaza política y espiritual del imperialismo estadounidense. Me refiero, lógicamente, a la sinfónica «Salutación del optimista» y, sobre todo, a la denuncia de su poema «A Roosevelt», que manifiesta explícitamente ese espiritualismo modernista que trata de superar el pragmático materialismo burgués. Ese descenso a la circunstancia histórica emparenta la temporalidad de Darío al compromiso hispánico del Machado de Campos de Castilla, en composiciones como «Del pasado efímero» y «El mañana efímero». Pero no me detendré en estas aproximaciones que requieren unas matizaciones muy peculiares ${ }^{29}$.

Más allá de esos poemas, cabe observar cómo Darío no logra mantenerse de continuo en ese éxtasis instantáneo donde el goce de la analogía cósmica le hace soslayar la sofocante temporalidad cotidiana. Incluso en un ámbito tan propicio para la contemplación analógica como la noche, a veces Darío no consigue establecer el puente que le haga comulgar con el «corazón del mundo», y es entonces cuando empieza a ser aplastado por la soledad del desterrado de ese universo cíclico y armónico. Leamos uno de los elocuentes «Nocturnos» de sus Cantos...:

Los que auscultasteis el corazón de la noche, los que por el insomnio tenaz habéis oído el cerrar de una puerta, el resonar de un coche lejano, un eco vago, un ligero rüido...

En los instantes del silencio misterioso, cuando surgen de su prisión los olvidados, en la hora de los muertos, en la hora del reposo, sabréis leer estos versos de amargor impregnados...

29 Para enunciar tan sólo la peculiar problemática de estos poemas «históricos» de Darío y Machado, baste decir que ni la «Salutación del optimista» es tan optimista como desearía el autor (aunque su creencia en la armonía universal y el tiempo cíclico superen ese desencanto momentáneo), ni «El mañana efímero» es tan pesimista como a primera vista parece. Dejemos aquí este cabo suelto para una elucidación futura. 
Como en un vaso vierto en ellos mis dolores de lejanos recuerdos y desgracias funestas, y las tristes nostalgias de mi alma, ebria de flores, y el duelo de mi corazón, triste de fiestas.

$Y$ el pesar de no ser lo que ya hubiera sido, la pérdida del reino que estaba para mí, el pensar que un instante pude no haber nacido, iy el sueño que es mi vida desde que yo nací! Todo esto viene en medio del silencio profundo en que la noche envuelve la terrena ilusión, y siento como un eco del corazón del mundo que penetra y conmueve mi propio corazón ${ }^{30}$.

Afincado habitualmente, dentro de su poesía, en esa extática y privilegiada analogía universal, el poeta se sorprende angustiosamente al comprobar la irreversibilidad de su existencia, la distancia insuperable entre su limitado y precario existir y la perfecta armonía del universo, cuyo rítmico corazón contrasta conmovedoramente con el irritante ruido de su conciencia insatisfecha. Nos encontramos, sí, ante uno de los poemas más existenciales de Darío: y digo existencial en cuanto que la conciencia del humano vivir individual con todas sus limitaciones aflora explícitamente en el texto a modo de urgente confesión personal y, a la vez, de paradigma universal sobre la condición humana.

Y esa experiencia dolorosamente irónica, tan cercana al tono habitual de Antonio Machado, aparece en este nuevo poema de Darío, «De otoño», como consecuencia directa de la acción implacable del tiempo sucesivo:

Yo sé que hay quienes dicen: ¿Por qué no canta ahora con aquella locura armoniosa de antaño? Ésos no ven la obra profunda de la hora, la labor del minuto y el prodigio del año.

Yo, pobre árbol, produje, al amor de la brisa, cuando empecé a crecer, un vago y dulce son. Pasó ya el tiempo de la juvenil sonrisa: ¡dejad al huracán mover mi corazón! ${ }^{31}$.

Preso por la conciencia del tiempo lineal e irreversible, el poeta se siente muy lejano de «aquella locura armoniosa de antaño», es decir, de aquellos momentos sublimes en que, por efecto de la poesía, podía remontar el vuelo hacia las cumbres de un tiempo cuasi-eterno y de una mirada reconciliadora con todo lo existente. Darío se acerca ahora, casi simultáneamente, a aquella experiencia machadiana de la fugitiva alegría, que «dos veces no pasa». Son casos extremos y realmente aislados en el conjunto de la producción dariana, pero suficientes para observar los dos polos existenciales en que

$30 \quad$ Op. cit., p. 141.

31 Op. cit., p. 138. La cursiva es mía. 
se debate su poesía. Como ejemplo rotundo de esa ironía trágica, remito directamente al último poema de los Cantos..., que sigue teniendo mucho de «vida», pero muy poco de «esperanza». Me refiero, naturalmente, a «Lo fatal». Si Darío, nadando en un mar de sensaciones, había accedido habitualmente a la sublime sensación de vivir (que, en su poesía, significa vivir en comunión sustancial con la vida del cosmos), ahora abominará de toda sensación, pues toda sensación le hablará de un tiempo irrevocable y destructor que nublará cualquier facultad de conocimiento y le presentará el antiguo Enigma de la existencia como un absoluto sinsentido. Máxima conciencia de desterrado y, por tanto, de abismal distancia con el mundo, regido por otro tiempo muy distinto al de su individual existencia:

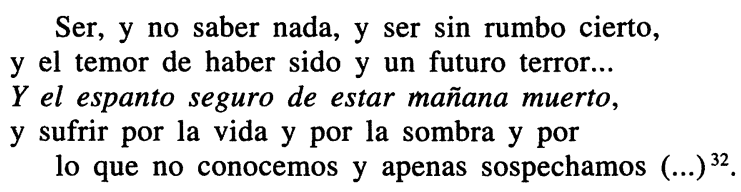

Estas caídas en la tenebrosa ironía existencial nos muestran el envés de la habitual afirmación analógica de Darío y nos acercan a la angustia temporalista de Machado. De modo análogo, en el poeta sevillano también podemos asistir a determinadas vivencias poéticas donde, gracias al sueño o fantasía creadora, en su ánimo se anula la conciencia del flujo destructor del tiempo y toma cuerpo una esperanza pletórica de promesas eternas. Recordemos el célebre «olmo seco» de Campos de Castilla, que un día podrá abrirse, junto al ánimo del poeta, «hacia la luz y hacia la vida». Pero, ciñéndonos a las Soledades, que son nuestro ámbito de trabajo en esta ocasión, advertiremos la intuición firme de una gozosa esperanza. Leamos este símbólico y misterioso poema XXXIV, cuyo misterio no impide captar en una primera lectura su intrínseca emotividad positiva y armónica:

Me dijo un alba de la primavera:

Yo florecí en tu corazón sombrío ha muchos años, caminante viejo que no cortas las flores del camino.

Tu corazón de sombra, ¿acaso guarda el viejo aroma de mis viejos lirios? ¿Perfuman aún mis rosas la alba frente del hada de tu sueño adamantino? Respondí a la mañana:

Sólo tienen cristal los sueños míos. Yo no conozco el hada de mis sueños; no sé si está mi corazón florido.

32 Op. cit., p. 147. La cursiva es mía. 
Pero si aguardas la mañana pura que ha de romper el vaso cristalino, quizás el hada te dará tus rosas, mi corazón tus lirios ${ }^{33}$.

El primer símbolo del poema, el alba de la primavera, representa la alegría y, con ella, la comunión del poeta con la vitalidad primaveral del mundo. Mediante sucesivos símbolos encadenados (el corazón sombrío, las flores del camino, el viejo aroma, los viejos lirios, las rosas, la alba frente, el sueño adamantino, el cristal, el corazón florido y, sobre todo, la mañana pura y el vaso cristalino), el texto nos va transportando hacia una alegría permanente que el poeta ha retenido a través del sueño (donde memoria vital e imaginación poética se funden). Y es este sueño, del que el yo-poético ahora no tiene conciencia plena, el que reaparecerá, con toda la intensidad de su alegría, el día de la mañana pura (la muerte), donde los sueños, almacenados en el vaso cristalino de la memoria, derramarán (en una supuesta vida eterna) su inagotable y duradera felicidad. De manera que, en virtud de la memoria y del sueño (o, mejor, de la memoria y el sueño fundidos), el poeta logra anular el flujo lineal y destructor del tiempo para instalarse en un mañana extático y plenamente dichoso.

Pero, a través de este sueño creador, también Machado podrá disfrutar en esta vida terrena de un instante donde la conciencia de la armonía universal conseguirá detener el flujo temporal de una tarde ya mortecina. Lo comprobaremos en el poema LXXIII:

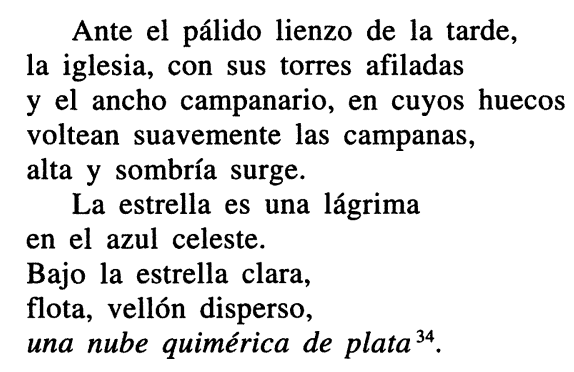

La nube iluminada por el fulgor de una estrella ha producido en el ánimo del poeta un efecto de instantánea plenitud espiritual, que le hace entrever la secreta armonía del cosmos tras la aparente diversidad y el irreparable acabamiento de todo lo existente. Cabe advertir que esta experiencia analógica, como todas las que hemos contemplado en estas líneas, no es el fruto de una especulación racional sobre la constitución del mundo, actividad que el poeta modernista rechaza frontalmente: es, por el con-

${ }^{33}$ Op. cit., p. 109.

34 Op. cit., p. 138. La cursiva es mía. 
trario, el efecto de un despliegue extraordinario de las potencias irracionales (sentimiento e imaginación, en este caso), pues irracional será, para todo poeta modernista y moderno, cualquier intuición de orden cosmológico o existencial.

En conclusión, podemos afirmar que, partiendo de un problema existencial y metafísico común (la pérdida del sentido de unidad del Universo y la conciencia del destierro del poeta en ese Universo y en esa sociedad), ambos autores modernistas, como tantos otros de este movimiento, oscilarán entre dos estados espirituales extremos (la analogía y la ironía), que conllevan una diversa captación del Tiempo y, con él, de la relación poeta-mundo. En Darío la consecución del estado analógico se produce habitualmente por la anulación del tiempo sucesivo a través de una recreación culturalista de diversos momentos históricos y artísticos, que congelan el Tiempo y convocan todas las épocas en un mismo instante de armonía y plenitud vital. Esa armonía cósmica y existencial es la que al Darío poeta le interesa plasmar en la mayor parte de sus versos, aunque no falta la constatación de la dificultad de acceder a esa analogía ni la misma expresión del fracaso irónico y el hundimiento del yo en las fuerzas destructoras del tiempo físico. En Antonio Machado el deseo de alcanzar la ansiada contemplación armónica le impele a una recreación de su pasado biográfico mediante el sueño y la memoria, sólo que en este recuento lo que resulta es una mayor conciencia del tiempo sucesivo y de su peso destructor sobre la vida humana, si bien en algunos casos el poeta accede a la ansiada armonía extática del instante, ya sea en la existencia terrena o en una vida eterna que, como tal, se encuentra ya libre de los embates del Tiempo.

La identidad del conflicto, así como la vía irracional de afrontarlo y de resolverlo en cada uno de estos poetas, nos revela la comunidad de rasgos cosmovisionarios y estéticos dentro del amplio y diverso panorama del modernismo hispánico. Creo que, además de situar a los dos grandes poetas en una esfera común de conflictos y de ideales, la consideración del problema temporal nos ha servido para evitar cualquier concepción del «noventayochismo» como una realidad literaria excluyente dentro del gran movimiento modernizador de la literatura hispánica en el fin-de-siglo. 